\title{
Nanostructured Carbon Materials: Synthesis and Applications
}

\author{
Alejandro Ansón-Casaos*, Enrique Garcia-Bordeje, Ana M. Benito, \\ Wolfgang K. Maser \\ Instituto de Carboquímica, ICB-CSIC, Miguel Luesma Castán, 50018 Zaragoza, Spain
}

\begin{abstract}
The family of carbon nanostructures includes a great number of forms with different properties derived from their reduced dimensionality. In particular, carbon nanotubes (CNTs) and graphene show special electronic, optical, mechanical and chemical properties that allow their potential application in new materials and devices. The real possibilities of pristine CNTs and graphene depend on their synthetic origin, which can be roughly classified into methods starting from graphite and chemical vapor deposition (CVD) processes. Applications of CNTs and graphene encompass electronics, energy devices, multifunctional composites, catalysis and sensors. Their reduced size and weight suggest potential uses in portable, wearable and mobile equipment with a high added value.
\end{abstract}

Keywords: Nanotube; Graphene; Electronic properties; Energy; Composite; Sensor

\section{Introduction}

Carbon nanomaterials have been central in the development of nanoscience and nanotechnology. The discovery of carbon nanotubes (CNTs) in 1991, ${ }^{1}$ and later of graphene, ${ }^{2}$ led to a new way of thinking in physics and materials science. Previously, the synthesis of fullerenes in the 80 s was also a revolution in chemistry and materials chemistry. ${ }^{3}$ Nowadays, carbon allotropes constitute a family that is the paradigm of how the reduction of dimensions to the nanoscale leads to quantum confinement, and thus to new physical properties, starting from electronics and optics, but also covering thermal, mechanical and chemical properties, and even fluid dynamics.

Many different methods have been utilized for the synthesis of carbon nanostructures, particularly in the cases of CNTs and graphene. Fullerenes were first discovered as the products of experiments in an electric arc discharge reactor with graphite electrodes. Also CNTs, both multi-walled (MWCNTs) and single-

*alanson@icb.csic.es 
walled (SWCNTs), were later observed by electron microscopy in an arcdischarge cathodic deposit. Chemical vapor deposition (CVD) methods have been successfully applied to the synthesis of CNTs from gaseous carbon precursors; high quality SWCNTs can be synthesized from graphite by laser ablation methods. Graphene was first prepared by exfoliation from graphite using an adhesive tape, while the current methods of production include CVD and liquid phase exfoliation of graphite, which commonly involves the interesting product known as graphene oxide (GO).

Applications of carbon nanomaterials are being investigated in many fields, some of them are already commercial, including additives for lithium ion batteries, new composites as new generation carbon fiber materials, etc. The utilization of carbon nanostructures opens up a wide field both in device miniaturization and in the improvement of the properties of bulk materials through their addition in small amounts.

In this mini-review, the most outstanding types of carbon nanostructures are first summarized and briefly described. All the nanomaterials mentioned, but especially CNTs and graphene, are currently the focus of a great number of scientific research works. The effects of dimensionality reduction are illustrated, specifically with the example of the optical spectra of SWCNTs. In the next section, the most common methods for the synthesis of CNTs and graphene are described. Knowledge on the nanostructures synthetic origin is often of paramount importance, as it limits the material properties and thus the potential applications. In the final section, the applications of CNTs and graphene are reviewed, mostly through studies developed at the Institute of Carbon Chemistry, ICB-CSIC. The applications cover the energy field, catalysis, polymer composites, inorganic composites, electronic applications, and sensors.

\section{The family of carbon nanomaterials}

Diamond and graphite are the classical forms of elemental carbon in the solid state; the crystalline organization of carbon atoms is respectively purely tetrahedral $\mathrm{sp}^{3}$ and trigonal $\mathrm{sp}^{2}$. The natural appearance of linear acetylenic carbon or carbine, the allotrope with pure linear sp geometry, is still a topic of discussion. The discovery of fullerenes in 1985 was one of the greatest hits of physics and chemistry in the last years of the $20^{\text {th }}$ century. ${ }^{3}$ The existence of fullerenes led to a revision of the basic concepts in carbon chemistry and general chemistry, since their characteristics of bonding and symmetry were unknown. In particular, the possibility of synthesizing closed hollow structures of only carbon atoms would have been unimaginable, as carbon bonds have to adapt to allow pentagonal rings. In fullerenes, the carbon bond geometry is between $\mathrm{sp}^{2}$ and $\mathrm{sp}^{3}$; the larger the number of atoms in the structure, the nearer to $\mathrm{sp}^{2}$. Soon after the discovery of fullerenes, their chemistry was studied, and it resulted to be extremely rich. Fullerenes can enclose metal atoms in their inner cavities, and can be also covered by 
one or several layers of ordered metal atoms. In addition, a great number of organic moieties can be bonded to fullerenes, resulting in new molecules.

MWCNTs were observed in 1991 during an investigation on fullerenes, ${ }^{1}$ while the existence of SWCNTs was demonstrated later in 1993. ${ }^{4,5}$ CNTs are formed by cylindrical seamless graphene layers, in which carbon atoms present nearly $\mathrm{sp}^{2}$ geometries, and are typically closed at the ends by fullerene-like caps. MWCNTs have 2-50 concentric layers, an interior diameter of 2-10 nm, an exterior diameter of $15-30 \mathrm{~nm}$, and an interlayer distance of $0.34 \mathrm{~nm}$, which is nearly identical to the separation between graphene layers in graphite. SWCNTs have diameters of 0.71$3 \mathrm{~nm}$ and easily join longitudinally to form bundles. Many different SWCNT conformations exist depending on the wall helicity. Despite having a great stability, CNT walls can be functionalized with many chemical groups, similarly to fullerenes. It can be stated that the discovery and study of CNTs has been central in the development of nanoscience and nanotechnology. Apart from fullerenes and carbon nanotubes, other related morphologies have been observed and studied, such as nanoonions and nanohorns. ${ }^{6,7}$

The idea of isolating a single graphene layer was realized in 2004 through mechanical exfoliation of graphite with an adhesive tape. ${ }^{2}$ A single $\mathrm{sp}^{2}$ carbon layer is very unstable and tends to fold, stack, or collapse. Therefore, a graphene layer can be only stabilized either on a solid substrate or in a liquid medium. Nowadays, graphene materials encompass a great variety of forms including single sheets on different solid substrates, ${ }^{8}$ multi-platelet graphene, ${ }^{9}$ graphene nanoribbons (GNRs), ${ }^{10} \mathrm{GO}$ and reduced graphene oxide (RGO). ${ }^{11,12}$ More recently, a great interest has been focused on graphene flakes with reduced lateral dimensions, which are generically called graphene quantum dots (GQDs). Other new nanomaterials such as carbon dots and nanodiamond complete the large family of carbon nanostructures. ${ }^{13}$

Nanostructured materials are low dimensional structures at the nanoscale. In other words, at least one of the spatial dimensions is reduced to the nanoscale. In such conditions, electrons are affected by spatial confinement and thus the electronic properties of the materials are modified. Whilst diamond and graphite are classical three dimensional (3D) structures, the thickness of a single graphene layer is $<1 \mathrm{~nm}$, so it is negligible against the lateral sheet dimensions (up to several $\mu \mathrm{m}$ ), thus graphene can be conceptually understood as a 2D nanostructure. The configuration of carbon atoms at the edges is relevant for the graphene sheet properties, particularly when lateral dimensions are very small, for example in GNRs. In CNTs, the length/diameter aspect ratio is typically so high that they can be considered 1D. Several different carbon nanostructures behave as 0D entities or quantum dots, including fullerenes, GQDs and carbon quantum dots. Finally, classical porous materials such as activated carbons (ACs) are sometimes considered as fractal structures with a reduced dimensionality between 2D and 3D. ACs can confine ordered atoms or molecules in their small pores and can act as molecular sieves.

One of the effects of dimensionality reduction and electronic confinement is the special optical response of SWCNTs. ${ }^{4-16}$ Figure 1 shows optical absorption spectra of 4 different SWCNT samples compared to a MWCNT sample and a graphitic 
material. All the starting powders were dispersed in a surfactant by ultrasound treatments and centrifugation. The graphitic soot (Figure 1a) absorbs light in the whole visible range, decreasing towards the infrared. This absorption profile is typical of carbon materials, in accordance with their black color, and related to collective electronic excitations along the sides of $\mathrm{sp}^{2}$ domains. Qualitatively similar spectra are measured for most of the carbon materials including MWCNTs (Figure 1b), as the single nanotube optical response is hindered by their multilayered structure. Apart from the typical spectral background of carbon materials, SWCNTs present particular absorption features, which are associated to the nanotube diameter and conformation. Electron confinement occurs in the so-called 1D van Hove singularities, and the permitted transitions between those particular electronic states give rise to the SWCNT absorption spectra. Each SWCNT type should give quite sharp spectral peaks. However, in typical SWCNT samples, which contain complex mixtures of many SWCNT types, wide bands are observed as a superposition of individual peaks (Figures 1c-f). It can be observed that absorption spectra are indicative of the SWCNT synthetic origin. Also, absorption features are sensitive to SWCNT purity, functionalization and structural quality. ${ }^{17-}$ 19

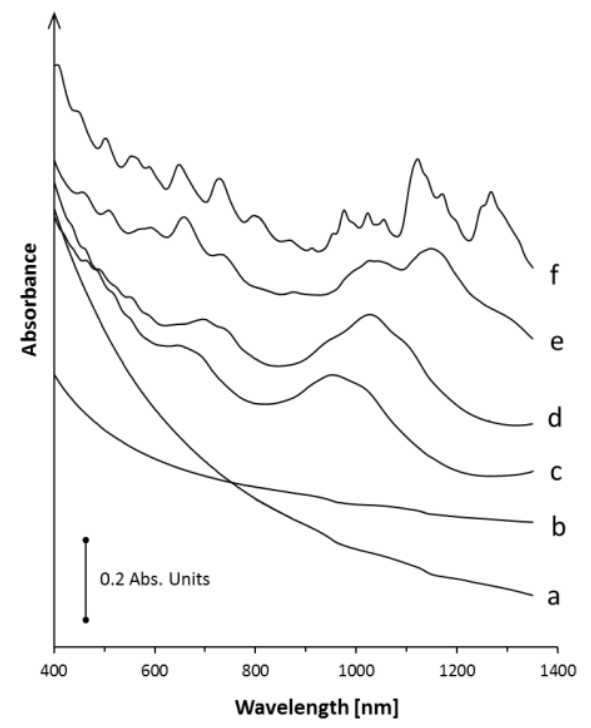

Fig. 1. Optical absorption spectra in the visible-near infrared region for surfactant-stabilized aqueous suspensions of different powder materials: a) graphitic soot, b) CVD MWCNTs, c) laser-grown SWCNTs, d) arc-discharge SWCNTs, e) CoMoCAT® SWCNTs, and f) HiPco® SWCNTs. Both CoMoCAT ${ }^{\circledR}$ and HiPco $\AA$ are commercial products synthesized by CVD methods. All suspensions were diluted in their respective aqueous media until reaching 0.4 absorbance units at $850 \mathrm{~nm}$. 
Other effects of electronic confinement are SWCNT fluorescence phenome$\mathrm{na},{ }^{20,21}$ the electronic structure of graphene and GNRs, the fluorescence of GQDs, and so on. Also, many other special properties (optical, mechanical, chemical) are derived from the particular electronic structure of carbon nanomaterials.

\section{Synthesis of carbon nanotubes and graphene}

The synthesis of CNTs can be performed by different methods, all of them based on the generation of small reactive molecular carbon units from either graphite or simple organic gases. Under certain process conditions, often in the presence of catalyst metal particles, the reactive carbon units combine to yield the cylindrical structures. Graphite evaporation can be effected in an electric arc reactor or by laser ablation methods, in which very high temperatures (> 5000 degrees) are locally achieved. On the other hand, decomposition of organic gases and the subsequent CVD process to give the nanostructures are performed in reactors at a constant temperature of around $1000{ }^{\circ} \mathrm{C}$ or lower.

The electric arc reactor method can be utilized for the synthesis of both fullerenes and CNTs under slightly different conditions. The graphite anode is evaporated when a high electrical current is passed in a sub-atmospheric pressure of certain ionizing gases. Fullerenes appear in the soot that covers the inner reactor walls after a discontinuous evaporation process without catalysts, and can be separated from the impurities by extraction in organics, particularly in toluene.

MWCNTs were first observed in the inner part of the cathodic deposit. The yield of the process for the synthesis of MWCNTs in the arc reactor can be improved just by slight modifications in the operation conditions for fullerene production. ${ }^{22,23}$ When the graphite anode contains certain metal catalysts (Fe, Ni, Co), SWCNTs appear in the material growing around the cathode and in the soot covering the inner reactor wall. ${ }^{4,5}$ Higher yields of the SWCNT production were achieved with binary metal catalyst mixtures, in particular Ni/Y. ${ }^{24}$ The temperatures between the electrodes during operation are very high ( $>5000$ degrees) but decrease very fast towards the reactor walls, generating strong gradients, so the growing conditions of the nanostructures are not determined. ${ }^{25}$ Arc-discharge CNTs show a high structural quality with a low number of defects, although the as-synthesized powders contain impurities (metal catalysts, graphite particles, amorphous carbon) that often have to be removed by purification post-treatments.

In laser synthesis methods, a graphite target is exposed to a laser beam, which increases the temperature of the solid until vaporization. From the gas phase, small carbon units react and can produce nanotubes, which settle on the chamber walls as soot. The laser source, which can be both pulsed and continuous, is often a YAG or a $\mathrm{CO}_{2}$ laser. ${ }^{26} \mathrm{~A}$ nearly identical synthesis concept can be developed with a solar concentrator. ${ }^{27}$ The resulting CNTs show high structural qualities, but the products contain impurities, similarly to arc-discharge CNTs.

In CVD methods, a gaseous precursor, typically $\mathrm{CO}, \mathrm{CH}_{4}$ or $\mathrm{C}_{2} \mathrm{H}_{2}$, acts as the carbon source, and the CNTs grow on catalyst metal particles. The method pro- 
vides a large number of variable parameters, including the carbon source, carrier gas, temperature, catalyst composition and catalyst preparation. ${ }^{28-32}$ The catalyst can be prepared from metal ion solutions and organometallic complexes, and it can be inserted in the reactor either as an aerosol or supported on silica, alumina and other materials. Since catalyst particles can be placed at defined positions on the support, it is possible to grow CNT forests, nanotubes on AFM cantilever tips and nanotubes between two electrodes. CVD methods allow the synthesis of many different CNT types and they are the preferred ones for industrial production.

CVD methods have been also successfully utilized for the synthesis of graphene. It has been demonstrated that the dimensions of the as-synthesized graphene domains $(1 \mu \mathrm{m}-1 \mathrm{~cm})$ can be on the order of that of highly crystalline graphite. $^{8}$ Graphene is first synthesized on catalyst metal sheets, typically made of copper, nickel and other metals, then it can be transferred to other supports, usually with a certain loss in its structural quality. CVD-grown graphene is expected to reach an industrial demand, particularly in electronic applications. ${ }^{8}$

Graphite exfoliation is the other route (top-down) for the synthesis of graphene. The micromechanical cleavage of graphite through the adhesive-tape method was utilized for the first experimental description of graphene, and it can be still useful in laboratory works. Other methodologies such as milling and chemical exfoliation in the liquid phase are the alternative for industrial applications in functional composite materials and inks. Physical milling of graphite leads to multi-platelet graphene materials that might be applied in polymer composites with improved frictional and mechanical properties. ${ }^{9}$ Liquid phase exfoliation has been widely utilized in laboratory research, and it is usually performed through a modified Hummers methods that involve a sequence of acid oxidant treatments. ${ }^{12}$ Liquid phase exfoliation is also possible in a surfactant or in organic solvents. A particular case of liquid phase exfoliation is the preparation of graphene nanoribbons from MWCNTs by unzipping in acid oxidant media. ${ }^{33,34}$ Small size GQDs can be also synthesized by chemical oxidation, and by electrochemical cleavage of graphite, a clean method that is interesting for biological applications.

\section{Applications of carbon nanotubes and graphene}

Applications of carbon nanostructures can be grouped, according to the appearance of the nanostructure, into those using individual nanostructures, assemblies of nanostructures, and composite materials. ${ }^{35}$ An special mention must be also made of processes that substantially modify the nanostructure properties, including functionalization, dispersion in a liquid, etc. ${ }^{35}$ In the following, the most direct classification is followed, which is based on the application field. Several topics are briefly reviewed, including energy devices, catalysis, light multifunctional polymers, and sensors. 


\section{Energy evices}

Carbon nanomaterials have been integrated in different parts of energy devices, sometimes as the whole component, but most commonly as additives to other active materials. Since carbon nanomaterials possess high aspect ratios and good electrical and thermal conductivities, they can act as wires for electronic transport and heat dissipation channels in devices such as batteries, electrochemical double layer capacitors (EDLCs), and solar cells.

CNTs, GO and RGO were soon tested as electrodes for EDLCs, also called supercapacitors. The powder materials can be compressed in a mold and impregnated with the electrolyte, which easily enters the mesoporous network created by the randomly oriented aggregated nanostructures. CNTs typically show nearly rectangular voltammograms, which are characteristic of electrodes with a capacitive behavior. Arc discharge SWCNTs and thermally oxidized SWCNTs reach capacitance values between 30 and $140 \mathrm{~F} \mathrm{~g}^{-1}$, showing that an alkaline electrolyte $(\mathrm{KOH})$ provides higher energy densities, while an acid electrolyte $\left(\mathrm{H}_{2} \mathrm{SO}_{4}\right)$ leads to higher power densities. ${ }^{36}$ The specific capacitance can be improved using aligned CVD CNTs, which show a higher specific surface area, but still the values remain lower than those obtained with some microporous activated carbons (ACs). Interestingly, a high capacitance at high currents and a power density maximum is reached with certain SWCNT/AC mixtures. ${ }^{37}$ High capacitances $\left(231 \mathrm{~F} \mathrm{~g}^{-1}\right)$ can be also reached with graphene-based porous electrodes prepared from GO and solid organic precursors. ${ }^{38}$ On the other hand, CNT fillers improve the thermal stability, potential window, porosity and durability of conducting polymers showing pseudo-capacitance, such as polypyrrole and polyaniline. ${ }^{39}$

Carbon nanotubes and graphene can be integrated in new-generation solar cells as active layers, ${ }^{40-42}$ electron acceptors, ${ }^{43}$ counter electrodes, ${ }^{44}$ electron transport layers (ETLs) and hole transport layers (HTLs). ${ }^{45,46}$ The utilization of CNTs and graphene as transparent conducting film (TCF) electrodes for indium tin oxide (ITO) substitution is limited by the requirements of electrical conductivity and transparency. ${ }^{47}$ Recently, a SWCNT synthesis process by aerosol CVD has provided high quality TCFs for solar cells. ${ }^{48}$ A polyanylyne/MWCNT (arc discharge) composite has been tested as the hole collecting electrode in photovoltaic textile applications. $^{49}$

Storage of gaseous fuels $\left(\mathrm{H}_{2}, \mathrm{CH}_{4}\right)$ and $\mathrm{CO}_{2}$ will probably have a great importance in the future energy scenario, which is expected to be based on clean renewable sources. The possibility of using carbon nanomaterials as adsorbents to improve the storage capacity of pressurized tanks was discussed for years, particularly in the case of hydrogen. Measurements of hydrogen adsorption in SWCNTs revealed low storage capacities, ${ }^{50,51}$ even if the adsorption was catalyzed by palladium nanoparticles. ${ }^{52,53}$ Finally, it has been demonstrated that gas capacity $\left(\mathrm{H}_{2}\right.$, $\mathrm{CH}_{4}$ and $\mathrm{CO}_{2}$ ) can be substantially improved in a pressurized storage tank at room temperature when the tank is filled with AC monoliths, compared to simple compression. $^{54}$ 
8 Alejandro Ansón-Casaos et al.

Fuel cells are being widely investigated as a clean solution for powering mobile devices and vehicles. Carbon nanostructures have been successfully tested as catalyst supports for several chemical reactions that take place in different types of fuel cells. Arc discharge SWCNTs were used as supports for platinum nanoparticles, and tested for the oxygen reduction reaction, reaching efficiencies similar to typical carbon black conducting supports. ${ }^{55}$ The Pt/SWCNT catalyst also demonstrated good activities for the oxidation of methanol and formic acid. ${ }^{56}$ The catalyst efficiencies depend on the metal nanoparticle size and crystalline structure, which is ultimately influenced by the carbon support characteristics. Macroscopic assemblies of SWCNTs such as thick films ("buckypapers") were tested as supports of $\mathrm{Pt} / \mathrm{Ru}$ nanoparticles, and the catalyst activity towards methanol oxidation was clearly dependent on the buckypaper preparation procedure. ${ }^{57}$

\section{Catalysis}

Apart from the catalytic reactions that take place in fuel cells, carbon nanomaterials can be utilized in other important chemical reactions. CVD MWCNTs and GO have been tested as supports of catalytic metal particles with controlled sizes. $\mathrm{Pd} / \mathrm{MWCNT}$ hybrids are active in C-C coupling and dehydrogenation reactions, ${ }^{56}$ and specially in alkene hydrogenations. ${ }^{59} \mathrm{Au} / \mathrm{MWCNT}$ catalysts have proved good activities in the selective hydrogenation of nitroaromatic derivatives. ${ }^{60}$ Also, alkene hydrogenation reactions have been selectively catalyzed by $\mathrm{Pd} / \mathrm{GO}$ catalysts. $^{61}$

$1 \mathrm{D}$ and 2D nanocarbons are excellent building blocks for 3D architectures with a developed porosity and catalytic interest. Some examples are monoliths coated with a layer of CNTs, ${ }^{62}$ monoliths coated with N-doped CNTs, ${ }^{63}$ and graphene aerogels. ${ }^{64} 3 \mathrm{D}$-structured nanomaterials can be applied as metal nanoparticle supports or metal-free catalysts. CNTs and N-doped CNTs have been loaded with Ru nanoparticles for the $\mathrm{CO}_{2}$ reduction with renewable $\mathrm{H}_{2}$ to produce $\mathrm{CH}_{4}{ }^{65-66}$ Nitrogen- and boron-doped carbon nanofibers (CNFs), and nanodiamond supported on graphene aerogels have been tested as metal-free catalysts in the propane dehydrogenation to produce propene. ${ }^{64,67} \mathrm{NH}_{3}$ decomposition to produce $\mathrm{H}_{2}$ can be catalyzed by metal nanoparticles on CNFs and N-doped CNFs. ${ }^{68}$ Water cleaning applications include the ozonation of organic pollutants on CNTs and CNFs as metal-free catalysts, ${ }^{69}$ and the reduction of nitrate and bromate on CNTs or CNFs as catalyst supports. ${ }^{70}$

\section{Multifunctional Materials}

Processing issues and applications of CNT and graphene polymer composites have been reviewed in previous NATO ASIs. ${ }^{71.72}$ The synthetic origin and functionali- 
zation greatly influence the resulting properties of the composite material, particularly in structural polymers such as polyether ether ketone (PEEK) and epoxies. ${ }^{73,74}$ Polymer composites are promising light materials for mobile applications in the aeronautical and automotive industry, since a vehicle weight reduction leads to important energy savings. In SWCNT/epoxy composites, the electrical properties and toughness are maximized through the non-covalent functionalization of the SWNTs with compatibility block copolymers, while the mechanical and thermal properties are maximized through covalent functionalization with amine moieties. The improvements in the electrical conductivity of structural polymers, maintaining their mechanical performance, are typically great enough for application of the composites in electrostatic charge dissipation and electromagnetic interference shielding. ${ }^{75}$ In addition, it has been observed that CNTs may act as radical scavengers in polymer systems, protecting the composite materials against the effects of gamma radiation. More specifically, the protective effects of arcdischarge SWCNTs, CVD MWCNTs and arc-discharge MWCNTs have been demonstrated. ${ }^{76-79}$

\section{Sensors and Biosensors}

The electronic properties, together with the high specific surface area, rich surface chemistry, optical properties, thermal stability and mechanical robustness allow the application of CNTs and graphene as sensitive materials. The properties of individual nanostructures can in part be translated into micro- and macroscopic systems including thin films, fibres, inks, buckypapers and composite materials, which often constitute the active part in the sensor system. Applications of sensors based on carbon nanostructures cover many sectors.

In resistive gas sensors, the resistance of the sensitive material changes upon exposure to the gas molecules through physical adsorption. For instance, a film of Pd-functionalized SWCNTs can act as the resistive channel for the reversible detection of $\mathrm{H}_{2},{ }^{80,81}$ and MWCNT films have been tested for the detection of $\mathrm{NO}_{2}{ }^{82}$ Also, chemically functionalized SWCNT films experience sensitive changes upon exposure to explosive components, ${ }^{83}$ and biologic agent simulants. ${ }^{84}$

Acoustic wave sensors measure the difference in wave propagation from an emitter to a detector through a tuneable guiding layer. In this type of sensors, CNTs and GO have been successfully tested as the sensitive layer for the detection of chemical warfare agents. ${ }^{85}$

Semiconducting SWCNTs or SWCNT films can work as channels in field effect transistors (FETs), and the device response is modified through the adsorption of molecules on the SWCNT surfaces. Therefore, appropriately designed SWCNT FETs are sensitive to biological molecules such as different DNA types and anabolic steroids. ${ }^{86-88}$

Another concept for specific biomolecule detection is based on electrochemical sensing, both by amperometric, ${ }^{89-92}$ and potentiometric methods. ${ }^{93,94}$ In a typical 
device, inks, films or papers of functional carbon nanostructures are deposited on a glassy carbon electrode for improving the device sensitivity.

Finally, strain sensors have to be considered, which can be utilized for the detection of pressure and movement. The most direct way for strain sensing is the use of piezoelectric materials. Other strategies include piezoresistive SWCNT composites, in which the electrical resistance greatly changes upon bending. ${ }^{95.96}$ The piezoresistive effect is maximized at SWCNT loadings near the electrical percolation threshold. ${ }^{97}$

\section{Summary and Outlook}

Nowadays, the methods for the synthesis of CNTs and graphene are wellstablished, and good quality materials can be obtained either directly after the synthesis process or applying purification treatments. Certain types of CNTs and graphene are fabricated in large amounts, allowing their use in industry. Even though improvements in the synthesis control and purification are still needed, scientific research in CNTs and graphene has mainly expanded towards the applications, covering a great number of technological fields. Some of the developed technological products have already reached the industry, and it is expected that many others will soon be ready for the market. In the meantime, other new forms of nanostructured carbons are being described, including GNRs, GQDs, nanocones and carbon dots. In all the cases, the nanostructure synthetic origin influences the properties and thus determines the applications. According to their potential, further developments in carbon nanostructures can be foreseen for the next years.

Acknowledgments The authors thank the organization of the NATO ASI taking place in Sozopol, Bulgaria from 12/09 to 20/09/2017. This work has been funded by MINECO and European Regional Development Fund (ENE 2016-79282-C5-1-R), Government of Aragon and European Social Fund (DGA-ESF-T66 "Grupo Consolidado").

\section{References}

[1] S. Iijima, Helical microtubules of graphitic carbon, Nature 354 (1991) 56-58.

[2] K. S. Novoselov, A. K. Geim, S. V. Morozov, D. Jiang, Y. Zhang, S. V. Dubonos, I. V. Grigorieva, and A. A. Firsov, Electric field in atomically thin carbon films, Science 306 (2004) 666-669.

[3] H. W. Kroto, J. R. Heath, S. C. O’Brien, R. F. Curl, and R. E. Smalley, C60: buckmisterfullerene, Nature 318 (1985) 162-163.

[4] S. Iijima, and T. Ichihashi, Single-shell carbon nanotubes of 1-nm diameter, Nature 363 (1993) 603-605.

[5] D. S. Bethune, C. H. Kiang, M. S. de Vries, G. Gorman, R. Savoy, J. Vasquez, and R. Beyers, Cobalt catalysed growth of carbon nanotubes with single-atomic-layer walls, Nature 363 (1993) 605-607.

[6] J. Bartelmess, and S. Giordani, Carbon nano-onions (multi-layer fullerenes): chemistry and applications, Beilstein J. Nanotechnol. 5 (2014) 1980-1998.

[7] N. Karousis, I. Suarez-Martinez, C. P. Ewels, and N. Tagmatarchis, Structure, properties, functionalization, and applications of carbon nanohorns, Chem. Rev. 116 (2016) 4850-4883. 
[8] S. Hofmann, P. Braeuninger-Weimer, and R. S. Weatherup, CVD-enabled graphene manufacture and technology, J. Phys. Chem. Lett. 6 (2015) 2714-2721.

[9] A. Chih, A. Ansón-Casaos and J.A. Puértolas, Frictional and mechanical behaviour of graphene/UHMWPE composite coatings, Tribol. Int. 116 (2017) 295-302.

[10] A. Martín, J. Hernández-Ferrer, L. Vázquez, M. T. Martínez, and A. Escarpa, Controlled chemistry of tailored graphene nanoribbons for electrochemistry: a rational approach to optimizing molecule detection, RSC Adv. 4 (2014) 132-139.

[11] C. Vallés, J. D. Núñez, A. M. Benito, and W. K. Maser, Flexible conductive graphene paper obtained by direct and gente annealing of graphene oxide paper, Carbon 50 (2012) 835-844.

[12] A. Taratan, A. Zobelli, A. M. Benito, W. K. Maser, and O. Stéphan, Revisiting graphene oxide chemistry via spatially-resolved electron energy loss spectroscopy, Chem. Mater. 28 (2016) 3741-3748.

[13] N. Nunn, M. Torelli, G. McGuire, and O. Shenderova, Nanodiamond: a high impact nanomaterial, Curr. Opin. Solid State Mater. Sci. 21 (2017) 1-9.

[14] H. Kataura, Y. Kumazawa, Y. Maniwa, I. Umezu, S. Suzuki, Y. Ohtsuka, and Y. Achiba, Optical properties of single-wall carbon nanotubes, Synth. Met. 103 (1999) 2555-2558.

[15] M. S. Strano, S. K. Doorn, E. H. Haroz, C. Kittrell, R. H. Hauge, and R. E. Smalley, Assignment of $(n, m)$ Raman and optical features of metallic single-walled carbon nanotubes, Nano Lett. 3 (2003) 1091-1096.

[16] R. B. Weisman, and S. M. Bachilo, Dependence of optical transition energies on structure for single-walled carbon nanotubes in aqueous suspension: an empirical Kataura plot, Nano Lett. 3 (2003) 1235-1238.

[17] M. E. Itkis, D. E. Perea, S. Niyogi, S. M. Rickard, M. A. Hamon, H. Hu, B. Zhao, and R. C. Haddon, Purity evaluation of as-prepared single-walled carbon nanotube soot by use of solution-phase near-IR spectroscopy, Nano Lett. 3 (2003) 309-314.

[18] M. T. Martinez, M. A. Callejas, A. M. Benito, M. Cochet, T. Seeger, A. Ansón, J. Schreiber, C. Gordon, C. Marhic, O. Chauvet, J. L. G. Fierro, and W. K. Maser, Sensitivity of single Wall carbon nanotubes to oxidative processing: structural modification, intercalation and functionalization, Carbon 41 (2003) 2247-2256.

[19] A. Ansón-Casaos, J. M. González-Domínguez, I. Lafragüeta, J. A. Carrodeguas, and M. T. Martínez, Optical absorption response of chemically modified single-walled carbon nanotubes upon ultracentrifugation in various dispersants, Carbon 66 (2014) 105-118.

[20] M. J. O’Connell, S. M. Bachilo, C. B. Huffman, V. C. Moore, M. S. Strano, E .H. Haroz, K .L. Rialon, P. J. Boul, W. H. Noon, C. Kittrell, J. Ma, R. H. Hauge, R. B. Weisman, and R. E. Smalley, Band gap fluorescence from individual single-walled carbon nanotubes, Science 297 (2002) 593-596.

[21] S. Lebedkin, F. Hennrich, T. Skipa, and M. M. Kappes, Near-onfrared photoluminescence of single-walled carbon nanotubes prepared by the laser vaporization method, J. Phys. Chem. B 107 (2003) 1949-1956.

[22] T. W. Ebbesen, and P. M. Ajayan, Large-Scale synthesis of carbon nanotubes, Nature 358 (1992) 220-222.

[23] D. T. Colbert, J. Zhang, S. M. McClure, P. Nikolaev, Z. Chen, J.H. Hafner, D. W. Owens, P. G. Kotula, and C. B. Carter, Growth and sintering of fullerene nanotubes, Science 266 (1994) 1218-1222.

[24] C. Journet, W. K. Maser, P. Bernier, A. Loiseau, M. Lamy de la Chapelle, S. Lefrant, P. Deniard, R. Lee, and J. E. Fischer, Large-scale production of single-walled carbon nanotubes by the electric-arc technique, Nature 388 (1997) 756

[25] H. Lange, K. Saidane, M. Razafinimanana, and A. Gleizes, Temperatures and C2 column densities in a carbon arc plasma, J. Phys. D: Appl. Phys. 32 (1999) 1024-1030.

[26] W. K. Maser, E. Muñoz, A. M. Benito, M. T. Martínez, G. F. de la Fuente, Y. Maniette, E. Anglaret, and J. L. Sauvajol, Production of high-density single-walled nanotube material by a simple laser-ablation method, Chem. Phys. Lett. 292 (1998) 587-593. 
12 Alejandro Ansón-Casaos et al.

[27] D. Laplaze, L. Alvarez, T. Guillard, J. M. Badie, and G. Flamant, Carbon nanotubes: dynamics of synthesis processes, Carbon 40 (2002) 1621-1634.

[28] M. Pérez-Mendoza, C. Vallés, W. K. Maser, M. T. Martínez, S. Langlois, J. L. Sauvajol, and A. M. Benito, Ni-Y/Mo catalyst for the large-scale CVD production of multi-wall carbon nanotubes, Carbon 43 (2005) 3034-3037.

[29] E. Terrado, E. Muñoz, W. K. Maser, A. M. Benito, and M. T. Martínez, Important parameters for the catalytic nanoparticles formation towards the growth of carbon nanotube aligned arrays, Diamond Relat. Mater. 16 (2007) 1082-1086.

[30] C. Vallés, M. Pérez-Mendoza, M. T. Martínez, W. K. Maser, and A. M. Benito, CVD production of doublé-wall carbon nanotubes, Diamond Relat. Mater. 16 (2007) 1087-1090.

[31] C. Vallés, M. Pérez-Mendoza, W. K. Maser, M. T. Martínez, L. Alvarez, J. L. Sauvajol, and A. M. Benito, Effects of partial and total methane flows on the yield and structural characteristics of MWCNTs produced by CVD, Carbon 47 (2009) 998-1004.

[32] E. Terrado, I. Tacchini, A. M. Benito, W. K. Maser, and M. T. Martínez, Optimizing catalyst nanoparticle distribution to produce densely-packed carbon nanotube growth, Carbon 47 (2009) 1989-2001.

[33] J. Hernández-Ferrer, P. Laporta, F. Gutiérrez, M. D. Rubianes, G. Rivas, M. T. Martínez, Multi-walled carbon nanotubes/graphene nanoribbons hybrid materials with superior electrochemical performance, Electrochem. Commun. 39 (2014) 26-29.

[34] M. Moreno-Guzman, A. Martín, M. C. Martín, T. Sierra, A. Ansón-Casaos, M. T. Martinez, A. Escarpa, Electrochemical behavior of hybrid carbon nanomaterials: the chemistry behind the electrochemistry, Electrochim. Acta 214 (2016) 286-294.

[35] W. Maser, A. M. Benito, E. Muñoz, and M. T. Martínez, Carbon nanotubes: from fundamental nanoscale objects towards functional nanocomposites and applications, NATO ASI Ser., Ser. B (2008) 101-119.

[36] F. Picó, J. M. Rojo, M. L. Sanjuán, A. Ansón, A. M. Benito, M. A. Callejas, W. K. Maser, and M. T. Martínez, Single-walled carbon nanotubes as electrodes in supercapacitors, J. Electrochem. Soc. 151(6) (2004) A831-A837.

[37] F. Picó, C. Pecharroman, A. Ansón, M. T. Martínez, and J. M. Rojo, Understanding carboncarbon composites as electrodes of supercapacitors, J. Electrochem. Soc. 154(6) (2004) A579-A586.

[38] L. Zhang, F. Zhang, X. Yang, G. Lang, Y. Wu, T. Zhang, K. Leng, Y. Huang, Y. Mo, A. $\mathrm{Yu}$, and Y. Chen, Porous 3D graphene-based bulk materials with exceptional high surface area and excellent conductivity for supercapacitors, Sci. Rep. 3 (2013) 1408.

[39] J. Hernández-Ferrer, A. Ansón-Casaos, and M. T. Martínez, Electrochemical synthesis and characterization of single-walled carbon nanotubes/polypyrrole films on transparent substrates, Electrochim. Acta 64 (2012) 1-9.

[40] E. Kymakis, and G. A. J. Amaratunga, Photovoltaic cells based on dye-sensitisation of single-wall carbon nanotubes in a polymer matrix, Sol. Energ. Mater. Sol. Cells. 80 (2003) 465472.

[41] E. Kymakis, and G. A. J. Amaratunga, Single-wall carbon nanotube/conjugated polymer photovoltaic devices, Appl. Phys. Lett. 80(1) (2002) 112-114.

[42] P. V. Kamat, Harvesting photons with carbon nanotubes, Nanotoday 1(4) (2006) 20-27.

[43] A. Kongkanand, R. Martínez-Domínguez, and P. V. Kamat, Single Wall carbon nanotube scaffolds for photoelectrochemical solar cells. Capture and transport of photogenerated electrons, Nano Lett. 7(3) (2007) 676-680.

[44] H. Li, K. Cao, J. Cui, S. Liu, X. Qiao, Y. Shen, and M. Wang, 14.7\% efficient mesoscopic perovskite solar cells using single walled carbon nanotubes/carbon composite counter electrodes, Nanoscale 8(12) (2016) 6379-6385.

[45] E. Kymakis, M. M. Strylianakis, G. D. Spyropoulos, E. Stratakis, E. Koudoumas, and C. Fotakis, Sol. Energ. Mater. Sol. Cells 96 (2012) 298-301. 
[46] E. Stratakis, K. Savva, D. Konios, C. Petridis, E. Kymakis, Improving the efficiency of organic photovoltaics by tuning the work function of graphene oxide hole transporting layers, Nanoscale 6 (2014) 6925-6931.

[47] A. Ansón-Casaos, R. Mis-Fernández, C. M. López-Alled, E. Almendro-López, J. Hernández-Ferrer, J. M. González-Domínguez, M. T. Martínez, Transparent conducting films made of different carbon nanotubes, processed carbon nanotubes, and graphene nanoribbons, Chem. Eng. Sci. 138 (2015) 566-574.

[48] I. Jeon, T. Chiba, C. Delacou, Y. Guo, A. Kaskela, O. Reynand, E. I. Kauppinen, S. Maruyama, and Y. Matsuo, Single-walled carbon nanotube film as electrode in indium-free planar heterojunction perovskite solar cells: investigation of electron-blocking layers and dopants, Nano Lett. 15 (2015) 6665-6671.

[49] A. Bedeloglu, P. Jimenez, A. Demir, Y. Bozkurt, W. K. Maser, and N. S. Sariciftci, Photovoltaic textile structure using polyaniline/carbon nanotube composite materials, J. Tex. I. 102(10) (2011) 857-862.

[50] A. Ansón, M. Benham, J. Jagiello, M. A. Callejas, A. M. Benito, W. K. Maser, A. Züttel, P. Sudan, and M. T. Martínez, Hydrogen adsorption on a single-walled carbon nanotube material: a comparative study of three different adsorption techniques, Nanotechnology 15 (2004) 1503-1508.

[51] A. Ansón, J. Jagiello, J. B. Parra, M. L. Sanjuán, A. M. Benito, W. K. Maser, and M. T. Martínez, Porosity, Surface área, Surface energy, and hydrogen adsorption in nanostructured carbons, J. Phys. Chem. B 108 (2004) 15820-15826.

[52] A. Ansón, E. Lafuente, E. Urriolabeitia, R. Navarro, A. M. Benito, W. K. Maser, and M. T. Martínez, Hydrogen capacity of palladium-loaded carbon materials, J. Phys. Chem. B 110 (2006) 6643-6648.

[53] A. Ansón, E. Lafuente, E. Urriolabeitia, R. Navarro, A. M. Benito, W. K. Maser, and M. T. Martínez, Preparation of palladium loaded carbon nanotubes and activated carbons for hydrogen sorption, J. Alloys Compounds 436 (2007) 294-297.

[54] M. Kunowsky, J. P. Marco-Lozar, F. Suárez-García, and A. Linares-Solano, Applications for $\mathrm{CO}_{2}$-activated carbon monoliths: I. gas storage, Int. J. Appl. Ceram. Technol. 12(S3) (2015) E121-E126.

[55] E. Lafuente, E. Muñoz, A. M. Benito, W. K. Maser, amd M. T. Martínez, Single-walled carbon nanotube-supported platinum nanoparticles as fuel cell electrocatalysts, J. Mater. Res. 21(11) (2006) 2841-2846.

[56] J. Solla-Gullón, E. Lafuente, A. Aldaz, M. T. Martínez, and J. M. Feliu, Electrochemical characterization and reactivity of Pt nanoparticles supported on single-walled carbon nanotubes, Electrochim. Acta 52 (2007) 5582-5590.

[57] J. M. Sieben, A. Ansón-Casaos, M. T. Martínez, and E. Morallón, Single-walled carbon nanotube buckypapers as electrocatalyst supports for metanol oxidation, J. Power Sources $242(2013) 7-14$.

[58] M. Cano, A. Benito, W. K. Maser, and E. Urriolabeitia, One-step microwave synthesis of palladium-carbon nanotube hybrids with improved catalytic performance, Carbon 49 (2001) 652-658.

[59] M. Cano, A. Benito, W. K. Maser, and E. Urriolabeitia, High catalytic performance of palladium nanoparticles supported on multiwalled carbon nanotubes in alkene hydrogenation reactions, New J. Chem. 37 (2013) 1968-1972.

[60] M. Cano, P. Villuendas, A. M. Benito, E. P. Urriolabeitia, and W. K. Maser, Carbon nanotube-gold nanoparticles as efficient catalyst for the selective hydrogenation of nitroaromatic derivatives to anilines, Materials Today Commun. 3 (2015) 104-113.

[61] M. Cano, A. M. Benito, E. P. Urriolabeitia, R. Arenal, and W. K. Maser, Reduced graphene oxide: firm support for catalytically active palladium nanoparticles and game changer in selective hydrogenation reactions, Nanoscale 5 (2013) 10189-10193. 
14 Alejandro Ansón-Casaos et al.

[62] L. Roldan, S. Armenise, Y. Marco, and E. Garcia-Bordeje, Control of nitrogen insertion during the growth of nitrogen-containing carbon nanofibers on cordierite monolith walls, Phys. Chem. Chem. Phys. 14 (2012) 3568-3575.

[63] E. García-Bordejé, I. Kvande, D. Chen, and M. Rönning, Carbon Nanofibers Uniformly Grown on $\gamma$-Alumina Washcoated Cordierite Monoliths, Adv. Mater. 18 (2006) 1589-1592.

[64] L. Roldan, A. M. Benito, and E. Garcia-Bordeje, Self-assembled graphene aerogel and nanodiamond hybrids as high performance catalysts in oxidative propane dehydrogenation, $J$. Mater. Chem. A 3 (2015) 24379-24388.

[65] L. Roldán, Y. Marco, and E. García-Bordejé, Origin of the excellent performance of Ru on nitrogen-doped carbon nanofibers for $\mathrm{CO}_{2}$ hydrogenation to $\mathrm{CH}_{4}$, ChemSusChem 10 (2017) $1139-1144$

[66] L. Roldán, Y. Marco, and E. García-Bordejé, Function of the support and metal loading on catalytic carbon dioxide reduction using ruthenium nanoparticles supported on carbon nanofibers, Chem CatChem 7 (2015) 1347-1356.

[67] Y. Marco, L. Roldán, E. Muñoz, and E. García-Bordejé, Carbon nanofibers modified with heteroatoms as metal-free catalysts for the oxidative dehydrogenation of propane, ChemSusChem 7 (2014) 2496-2504.

[68] S. Armenise, L. Roldán, Y. Marco, A. Monzón, and E. García-Bordejé, Elucidation of catalyst support effect for $\mathrm{NH}_{3}$ decomposition using Ru nanoparticles on nitrogenfunctionalized carbon nanofiber monoliths, J. Phys. Chemi. C 116 (2012) 26385-26395.

[69] J. Restivo, J.J.M. Orfão, M.F.R. Pereira, E. Garcia-Bordejé, P. Roche, D. Bourdin, B. Houssais, M. Coste, and S. Derrouiche, Catalytic ozonation of organic micropollutants using carbon nanofibers supported on monoliths, Chem. Eng. J. 230 (2013) 115-123.

[70] T. Yuranova, L. Kiwi-Minsker, C. Franch, A. E. Palomares, S. Armenise, and E. GarciaBordeje, Nanostructured catalysts for the continuous reduction of nitrates and bromates in water, Ind. Eng. Chem. Res. 52 (2013) 13930-13937.

[71] W. K. Maser, A. M. Benito, P. Castell, R. Sainz, M. T. Martinez, M. Naffakh, C. Marco, G. Ellis, M. A. Gómez, Carbon nanotube composite materials: opportunities and processing issues, NATO ASI Ser., Ser. B (2009) 181-198.

[72] C. Vallés, P. Jiménez, E. Muñoz, A. M. Benito, and W. K. Maser, Graphene: 2D-building block for functional nanocomposites, NATO ASI Ser., Ser. B (2011) 143-148.

[73] A. M. Diez-Pascual, J. M. Gonzalez-Dominguez, Y. Martinez-Rubi, M. Naffakh, A. Ansón, M. T. Martínez, B. Simard, and M. A. Gómez, Synthesis and properties of PEEK/carbon nanotube nanocomposites, in: Polymer nanotube nanocomposites: synthesis, properties, and applications (Scrivener Publishing LLC), pp. 281-313.

[74] J. M. Gonzalez-Dominguez, A. M. Diez-Pascual, A. Ansón-Casaos. M. A. Gómez-Fatou, and M. T. Martinez, Functionalization strategies for single-walled carbon nanotubes integration in epoxy matrices, in: Polymer nanotube nanocomposites: synthesis, properties, and applications: second edition (Scrivener Publishing LLC), pp. 281-313.

[75] A. Ansón-Casaos, F. J. Pascual, C. Ruano, N. Fernández-Huerta, I. Fernández-Pato, J. C. Otero, J. A. Puértolas, and M. T. Martínez, Electrical conductivity and tensile properties of block-copolymer wrapped single-walled carbon nanotube/poly(methyl methacrylate) composites, J. Appl. Polym. Sci. 132(9) (2015) 41547.

[76] P. Castell, F. J. Medel, M. T. Martinez, and J. A. Puértolas, Influence of gamma irradiation on carbon nanotube-reinforced polypropylene, J. Nanosci. Nanotechnol. 9 (2009) 6055-6063.

[77] M. J. Martínez-Morlanes, P. Castell, V. Martínez-Nogués, M. T. Martinez, P. J. Alonso, and J. A. Puértolas, Effects of gamma-irradiation on UHMWPE/MWNT nanocomposites. Compos. Sci. Technol. 71 (2011) 282-288.

[78] M. J. Martínez-Morlanes, P. Castell, P. J. Alonso, M. T. Martinez, and J. A. Puértolas, Multi-walled carbon nanotubes acting as free radical scavengers in gamma-irradiated ultrahigh molecular weight polyethylene composites, Carbon 50 (2012) 2442-2452.

[79] P. Castell, M. J. Martínez-Morlanes, P. J. Alonso, M. T. Martinez, and J. A. Puértolas, A novel approach to the chemical stabilization of gamma-irradiated ultrahigh molecular weight 
polyethylene using arc-discharge multi-walled carbon nanotubes, J. Mater. Sci. 48 (2013) $6549-6557$.

[80] I. Sayago, E. Terrado, E. Lafuente, M. C. Horrillo, W. K. Maser, A. M. Benito, R. Navarro, E. P. Urriolabeitia, M. T. Martinez, and J. Gutierrez, Hydrogen sensors based on carbon nanotubes thin films, Synth. Metals 148 (2005) 15-19.

[81] I. Sayago, E. Terrado, M. Aleixandre, M. C. Horrillo, M. J. Fernández, J. Lozano, E. Lafuente, W. K. Maser, A. M. Benito, M. T. Martinez, J. Gutiérrez, and E. Muñoz, Novel selective sensors based on carbon nanotube films for hydrogen detection, Sens. Actuat. B 122 (2007) 75-80.

[82] I. Sayago, H. Santos, M. C. Horrillo, M. Aleixandre, M. J. Fernández, E. Terrado, I. Tacchini, R. Aroz, W. K. Maser, A. M. Benito, M. T. Martinez, J. Gutiérrez, and E. Muñoz, Carbon nanotube networks as gas sensors for $\mathrm{NO}_{2}$ detection, Talanta 77 (2008) 758-764.

[83] J. M. Schnorr, D. van der Zwaag, J. J. Walish, Y. Weizmann, and Timothy M. Swager, Sensory arrays of covalently functionalized single-walled carbon nanotubes for explosive detection, Adv. Funct. Mater. 23 (2013) 5285-5291.

[84] D. Kumar, P. Jha, A. Chouksey, J. S. B. S. Rawat, R. P. Tandon, and P. K. Chaudhury, 4(hexafluoro-2-hydroxy isopropyl)aniline functionalized highly sensitive flexible SWCNT sensor for detection of nerve agent simulant dimethyl methylphosphonate, Mater. Chem. Phys. 181 (2016) 487-494.

[85] I. Sayago, D. Matatagui, M. J. Fernández, J. L. Fontecha, I. Jurewicz, R. Garriga, and E. Muñoz, Graphene oxide as sensitive layer in Love-wave Surface acoustic wave sensors for the detection of chemical warfare agent simulants, Talanta 148 (2016) 393-400.

[86] M. T. Martinez, Y. Tseng, N. Ormategui, I. Loinaz, R. Eritja, and J. Bokor, Label-free DNA biosensors based on functionalized carbon nanotube field effect transistors, Nano Lett. 9(2) (2009) 530-536.

[87] M. T. Martinez, Y. Tseng, J. P. Salvador, M. P. Marco, N. Ormategui, I. Loinaz, and J. Bokor, Electronic anabolic steroid recognition with carbon nanotube field effect transistors, ACS Nano 4(3) (2010) 1473-1480.

[88] M. T. Martinez, Y. Tseng, M. González, and J. Bokor, Streptavidin as CNTs and DNA linker for the specific electronic and optical detection of DNA hybridization, J. Phys. Chem. C 116 (2012) 22579-22586.

[89] A. Martín, J. Hernández-Ferrer, L. Vázquez, M. T. Martínez, and A. Escarpa, Controlled chemistry of tailored graphene nanoribbons for electrochemistry: a rational approach to optimizing molecule detection, RSC Adv. 4 (2014) 132-139.

[90] M. Eguílaz, A. Gutiérrez, F. Gutierrez, J.M. González-Domínguez, A. Ansón-Casaos, J. Hernández-Ferrer, N. F. Ferreyra, M. T. Martinez, and G. Rivas, Covalent functionalization of single-walled carbon nanotubes with polytyrosine: characterization and analytical applications for the sensitive quantification of polyphenols, Anal. Chim. Acta 909 (2016) 51-59.

[91] M. Eguílaz, F. Gutierrez, J. M. González-Domínguez, M. T. Martínez, and G. Rivas, Singlewalled carbon nanotubes covalently functionalized with polytyrosine: a new material for the development of NADH-based biosensors, Biosens. Bioelectron. 86 (2016) 308-314.

[92] F. A. Guitierrez, J. M. Gonzalez-Dominguez, A. Ansón-Casaos, J. Hernández-Ferrer, M. D. Rubianes, M. T. Martinez, and G. Rivas, Single-walled carbon nanotubes covalently functionalized with cysteine: a new alternative for the highly sensitive and selective Cd(II) quantification, Sens. Actuat. B 249 (2017) 506-514.

[93] R. Hernández, J. Riu, J. Bobacka, C. Vallés, P. Jiménez, A. M. Benito, W. K. Maser, and F. $\mathrm{X}$. Rius, Reduced graphene oxide films as solid transducers in potentiometric all-solid-state ion-selective electrodes, J. Phys. Chem. C 116 (2012) 22570-22578.

[94] R. Hernández, C. Vallés, A. M. Benito, W. K. Maser, F. X. Rius, and J. Riu, Graphenebased potentiometric biosensor for the immediate detection of living bacteria, Biosens. Bioelectron. 54 (2014) 553-557. 
16 Alejandro Ansón-Casaos et al.

[95] A. Ferreira, J. G. Rocha, A. Ansón-Casaos, M. T. Martinez, F. Vaz, and S. LancerosMendez, Electrochemical performance of poly(vinylidene fluoride)/carbon nanotube composites for strain sensor applications, Sens. Actuat. A 178 (2012) 10-16.

[96] J. M. Gonzalez-Dominguez, A. Ansón-Casaos, M. T. Martinez, A. Ferreira, F. Vaz, and S. Lanceros-Méndez, Piezoresistive response of Pluronic-wrapped single-wall carbon nanotubeepoxy composites, J. Intell. Mater. Syst. Struct. 23(8) (2012) 909-917.

[97] A. Ferreira, M. T. Martinez, A. Ansón-Casaos, L. E. Gómez-Pineda, F. Vaz, S. LancerosMendez, Relationship between electrochemical response and percolation threshold in carbon nanotube/poly(vinylidene) composites, Carbon 61 (2013) 568-576. 